\title{
Endometrial osseous metaplasia in a case of abnormal uterine bleeding
}

\author{
Himleena Gautam ${ }^{1 *}$, Alaka Goswami ${ }^{1}$, Papari Goswami², Kamal Kumar Kathar ${ }^{1}$
}

\author{
${ }^{1}$ Department of Obstetrics and Gynaecology, Apollo Hospitals, Guwahati, Assam, India \\ ${ }^{2}$ Department of Pathology, Apollo Hospitals, Guwahati, Assam, India
}

Received: 29 August 2019

Accepted: 30 September 2019

\section{*Correspondence:}

Dr. Himleena Gautam,

E-mail: himleenaj@gmail.com

Copyright: () the author(s), publisher and licensee Medip Academy. This is an open-access article distributed under the terms of the Creative Commons Attribution Non-Commercial License, which permits unrestricted non-commercial use, distribution, and reproduction in any medium, provided the original work is properly cited.

\begin{abstract}
Endometrial osseous metaplasia is an uncommon pathology with varied clinical symptoms. Its pathogenesis is not exactly known and has a benign course. Here we present a case of a 42 -year-old female with abnormal uterine bleeding who did not respond to medical management. On ultrasonography, suspected endometrial calcification was seen. Patient opted for hysterectomy and the biopsy report showed endometrial osseous metaplasia. Thus, in this case of menometrorrhagia and dysmenorrhoea, the cause was found to be osseous metaplasia.
\end{abstract}

Keywords: Dysmenorrhoea, Endometrial, Metaplasia, Menometrorrhagia, Osseous

\section{INTRODUCTION}

Osseous metaplasia of endometrium is a rare benign condition with presence of mature or immature bone in the endometrium. Its estimated incidence is around 3/10,000. ${ }^{1}$ Till date around 90 cases has been reported. Though many theories have been postulated, the most accepted theory of its pathophysiology is metaplasia of the endometrial stromal cells, particularly fibroblasts, into bone forming osteoblasts. ${ }^{2}$ This may occur in response to inflammation or repair process induced by abortion, as many cases show an association with an antecedent spontaneous or induced abortion. ${ }^{3,4}$ Patients may present with abnormal uterine bleeding (AUB), dysmenorrhoea, pelvic pain, vaginal discharge, secondary infertility or may be asymptomatic also. ${ }^{3,4}$

\section{CASE REPORT}

A 42-year-old multipara patient came to the Obstetrics and Gynaecology OPD with complaint of menometrorrhagia and dysmenorrhoea for 4 years with continuous bleeding per vagina for 1 month. She is para 4 with 3 vaginal deliveries and one caesarean section which was done 16 years back. She is a known case of type II diabetes mellitus, controlled on diet. She was given combined oral contraceptives along with antifibrinolytic agent (tranaxemic acid) for her complaints. Dilatation and curettage (D and C) were done 2 years back and emdpmetrial biopsy showed proliferative endometrium. But she did not have much relief from symptoms with these medications. She had no significant past or family history. Investigations showed mild anemia with high blood sugar levels, for which oral iron and insulin was started. Ultrasonography (USG) showed bulky uterus with calcification in lower uterine endometrium (Figure 1). After proper counseling and explaining all possible treatment options, the patient opted for hysterectomy.

Total laparoscopic hysterectomy was done. Uterus was bulky with cut section showing hard, bone like tissue in the endometrium (Figure 2). Bone like tissue was also 
seen in myometrium. HPE showed adenomyotic changes in endomyometrium with bony trabeculae and areas of stromal cells in endometrium, thus confirming osseous metaplasia of endometrium (Figure 3).

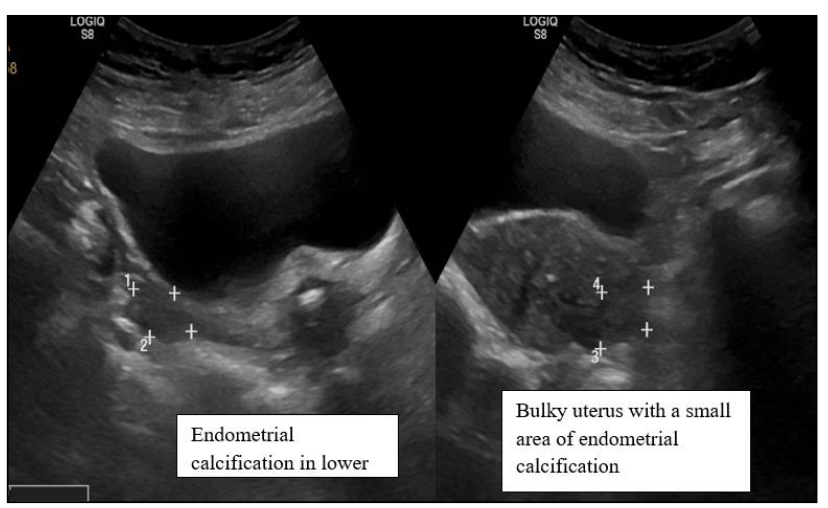

Figure 1: Ultrasonography showing bulky uterus with areas of endometrial calcification.

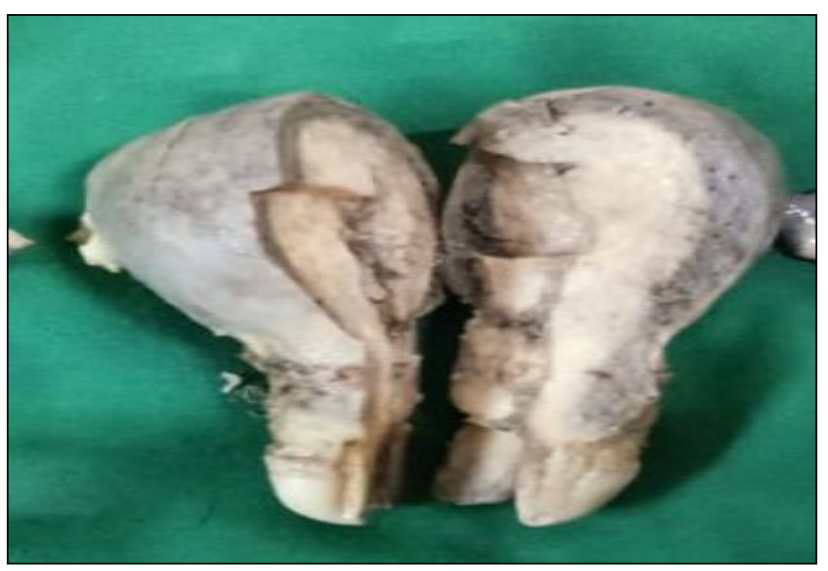

Figure 2: Cut section of uterus showing bone like areas in endo-myometrium.

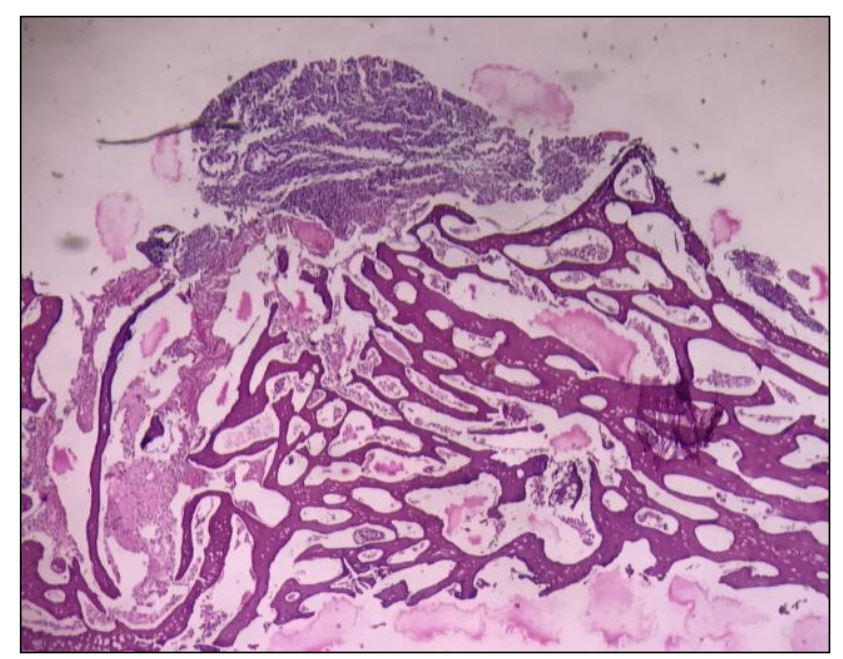

Figure 3: Dark purple areas showing bony trabeculae with endometrial glands and stroma in the top

\section{DISCUSSION}

Endometrial osseous metaplasia is mostly seen in reproductive age group, and may be associated with similar changes in cervix, vagina and ovary. ${ }^{5-7}$ Various hypothesis have been postulated for its etiology, which include metaplasia of uterine fibrobalsts into osteoblasts, prolonged estrogenic stimulation, chronic endometritis, pyometra, dystrophic calcification in retained products of conception and post abortive endometritis. ${ }^{2,3,8}$ Endometrial tuberculosis can also cause osseous metaplasia. $^{9}$ No association has been found of this condition with high levels of serum calcium.

Another concept is that superoxide radical superoxide dismutase system, which has an important role in endometrial differentiation, may be functional in osseous metaplasia. Endometrium deficient in protective superoxide dismutase activity may perhaps present a long-lasting insult to the multipotential stromal cells, and this may therefore transform these cells into osteoblasts. ${ }^{10}$

Patients present with various menstrual and pelvic symptoms. USG helps to diagnose the presence of bony tissue in the uterus. It usually shows characteristic hyperechoic appearance of bony tissue, as seen in this case. However gold standard method of diagnosis is hysteroscopy. ${ }^{11}$ In many cases, no tissue reaction is found in the endometrial tissue and the endometrium shows normal regular cyclical changes. ${ }^{2}$ Operative hysteroscopy is done in cases of infertility and in symptomatic patients. ${ }^{12}$ Hysterectomy is another mode of treatment. This condition may have a pre-neoplastic potential and may be associated with malignancy. ${ }^{13}$

Differential diagnosis of this disorder include endometrial tuberculosis, IUCD, malignant mixed mullerian tumour of endometrium and retained fetal bones after abortion.

\section{CONCLUSION}

Endometrial osseous metaplasia is a rare endogeneous pathological condition which is frequently undiagnosed or misdiagnosed. It is important to know this entity for proper management and to consider the non-neoplastic nature of this condition to avoid misinterpretation as malignant mixed mullerian tumor of the uterus.

Funding: No funding sources

Conflict of interest: None declared

Ethical approval: Not required

\section{REFERENCES}

1. Adamson NE, Sommers SC. Endometrial ossification: report of two cases. Am J Obstet Gynecol. 1954;67:187-90.

2. Umashankar T, Patted S, Handigund R. Endometrial osseous metaplasia: Clinicopathological study of a 
case and literature review. J Hum Reprod Sci. 2010;3:102-4.

3. Bhatia NN, Hoshiko MG. Uterine osseous metaplasia. Obstet Gynecol. 1982;60:256-9.

4. Bahçeci M, Demirel LC. Osseous metaplasia of the endometrium: a rare cause of infertility and its hysteroscopic management. Hum Reprod. 1996;11:2537-9.

5. Bedaiwy MA, Goldberg JM, Biscotti CV. Recurrent osseous metaplasia of the cervix after loop electrosurgical excision. Obstet Gynecol. 2001;98:968-70.

6. Campo S, Campo V, Zannoni GF, Gambadauro P. Simultaneous ovarian and endometrial osseous metaplasia: A case report. J Reprod Med. 2007;52:241-2.

7. Landim FM, Tavares JM, de Melo Braga DN, da Silva JE, Jr, Bastos Filho JB, Feitosa RG. Vaginal osseous metaplasia. Arch Gynecol Obstet. 2009;279:381-4

8. Shimizu M, Nakayama M. Endometrial ossification in a postmenopausal woman. J Clin Pathol. 1997;50:171-2.

9. Shroff CP, Kudterkar NG, Badhwar VR. Endometrial ossification- report of three cases with literature review. Indian J Pathol Microbiol. $1985 ; 28: 71-4$.
10. Sugino N, Shimamura K, Takiguchi S, Tamura H, Ono M, Nakata M, et al. Changes in activity of superoxide dismutase in the human endometrium throughout the menstrual cycle and in early pregnancy. Hum Reprod. 1996;11:1073-8.

11. Lainas T, Zorzovilis I, Petsas G, Alexopoulou E, Lainas G, Ioakimidis T. Osseous metaplasia: case report and review. Fertil Steril. 2004;82:1433-5.

12. Madaan M, Suman S, Sharma R, Kapoor N, Garg P, Raj SS. Osseous metaplasia of the endometrium and successful hysteroscopic resection: report of two cases and a review of the literature. Asian $\mathrm{J}$ Endosc Surg. 2015;8(1):63-6.

13. Nicolae A, Preda O, Nogales FF. Endometrial metaplasias and reactive changes: a spectrum of altered differentiation. J Clin Pathol. 2011;64:97-106.

Cite this article as: Gautam $\mathrm{H}$, Goswami A, Goswami P, Kathar KK. Endometrial osseous metaplasia in a case of abnormal uterine bleeding. Int J Reprod Contracept Obstet Gynecol 2019;8:4596-8. 